Бахновский Александр Викторович

кандидат юридических наук, доцент

кафедры международного права

Северо-Кавказского филиала Российского

государственного университета правосудия

\section{ПОСТАНОВЛЕНИЯ ЕВРОПЕЙСКОГО СУДА ПО ПРАВАМ ЧЕЛОВЕКА КАК ФАКТОР РАЗВИТИЯ ОТЕЧЕСТВЕННОЙ СУДЕБНОЙ ПРАКТИКИ: АКТУАЛЬНЫЕ ВОПРОСЫ ИМПЛЕМЕНТАЦИИ, ПЕРСПЕКТИВЫ ПРИМЕНЕНИЯ}

\section{Аннотация:}

В статье рассмотрены особенности имплементации судебной практики Европейского суда по правам человека в правовую систему России. Выполнен обзор наиболее значимых актов Верховного и Конституционного судов РФ по указанию правоприменителю на необходимость использования и учета постановлений Европейского суда по правам человека при отправлении правосудия. Актуальность исследования определяется переломным моментом во взаимодействии Российской Федерации и Совета Европы: международная организация, лишив нашу делегацию права голоса в Парламентской ассамблее, предрекает исключение из своего состава ввиду неуплаты обязательных членских взносов. Российская Федерация, в свою очередь, отказывается выплачивать взносы из-за лишения возможности реализовать свои права на высказывание позиции и диалог. Выход (или исключение) из состава Совета Европы автоматически повлечет нивелирование обязательств по исполнению положений Конвенции о защите прав и свобод 1950 г., в том числе по учету практики Европейского суда по правам человека. В результате все достижения отечественной практики и наработки высших судебных инстанций по усилению гарантий прав человека могут потерять нынешнее значение. По итогам анализа делается вывод о важности сохранения накопленного опыта взаимодействия с Европейским судом по правам человека (результатов имплементации), но при условии обеспечения полноценного статуса Российской Федерации как члена Совета Европы.

Ключевые слова:

права человека, Европейский суд по правам человека, международное право, судебная система, практика, имплементация, конституция, Совет Европы.
Bakhnovsky Aleksandr Viktorovich

PhD in Law, Associate Professor, International Law Department,

North Caucasus branch of

Russian State University of Justice

\section{THE EUROPEAN COURT OF HUMAN RIGHTS JUDGEMENTS AS A FACTOR IN RUSSIAN CASE-LAW DEVELOPMENT: RELEVANT ISSUES OF IMPLEMENTATION, PROSPECTS FOR APPLICATION}

Summary

The study deals with the implementation of European Court of Human Rights judgements in the Russian legal system. The author reviews the most significant rulings of the Supreme and Constitutional Courts of the Russian Federation on the need for the law enforcement officer to use and take into account the European Court of Human Rights judgements in the administration of justice. The relevance of the study is determined by a turning point in the interaction of the Russian Federation with the Council of Europe: having deprived the Russian delegation of the right to vote in the Parliamentary Assembly, the international organization predicts Russia's exclusion from its membership due to the non-payment of mandatory membership fees. The Russian Federation, in turn, refuses to pay the fee since it is deprived of opportunities to exercise its rights to speak out and hold a dialog. The withdrawal (or exclusion) from the Council of Europe would automatically entail removing obligations to implement the provisions of the 1950 European Convention for the Protection of Human Rights and Fundamental Freedoms, including the case-law of the European Court of Human Rights. As a result, all the achievements of Russian case-law and the best practices of higher courts to strengthen human rights guarantees may become irrelevant. The author concludes that it is important to maintain the experience of cooperation with the European Court of Human Rights (implementation results), but the Russian Federation should preserve the full status of a member of the Council of Europe.

Keywords human rights, European Court of Human Rights, international law, judiciary, case-law, implementation, the Constitution, the Council of Europe.

Множественность подходов к восприятию современного международного права обусловлена историей его становления после Второй мировой войны: государства определили несколько наиболее важных сфер взаимодействия, среди которых были экономическая (что представлялось жизненно необходимым в условиях разрушений от военных действий) и гуманитарная (защита ценнейшего ресурса - человека). Если в экономическом направлении шаги государств были очевидны и предсказуемы в части предоставления финансирования и его освоения, то гуманитарное (социальное) взаимодействие не могло иметь четкого плана реализации по причине различного подхода к восприятию системы прав человека и практики их защиты в национальном 
праве. Постепенное развитие единых стандартов на международном универсальном $(\mathrm{OOH})$ и региональном (Совет Европы) уровнях были последовательными и осторожными, что оправдывалось поставленной задачей - важна была не скорость формальных изменений, а улучшение правового статуса гражданина и личности.

В рамках принятых обязательств государства - члены Совета Европы признали юрисдикцию Европейского суда по правам человека (далее - ЕСПЧ) как органа, призванного контролировать правильность применения Конвенции о защите прав человека и основных свобод 1950 г. [1] (далее - Конвенция). Ввиду политического и идейного противостояния диалог СССР и Запада проходил в непростых условиях, что не позволило предшественнику современной России стать полноправным участником указанной региональной международной организации. Лишь в 1998 г. наша страна ратифицировала [2] Конвенцию, признав в соответствии с Конституцией России [3] ее положения частью своей правовой системы.

Однако фрактическое признание и полноценная реализация закрепленных прав и свобод оказались отдаленными друг от друга категориями. Выработанная ЕСПЧ практика учитывала исторический опыт государств-участников и их традиции, ввиду чего воспринималась странами как органичное продолжение собственных представлений и идей. Для Российской Федерации большинство подходов по расширительному толкованию международных стандартов прав человека были сложны для восприятия из-за невозможности быстрого смещения акцентов. Следует согласиться с мнением С.А. Егорова в части того, что международное и внутригосударственное право никогда не смогут находиться в условиях идеального баланса по причине неготовности последнего обеспечить реализацию норм международного права в их истинном значении [4, с. 100].

Важно также определить порядок проведения реформы внутринационального права, т. е. как именно будут реализованы изменения. Например, подход профессора М.Н. Марченко, заключающийся в том, что «право создается судом, а законодатель затем подхватывает созданное» [5], в данном случае неприменим: отечественная система права должна была и обновить нормативную базу, и предоставить «благодатную почву» для осуществления изменений с учетом чужого правоприменительного опыта (имплементации).

По мнению В.И. Червонюк, понятие «имплементация» (от англ. implementation - 'осуществление', 'выполнение') сводится к «фактическому обеспечению реализации исполнения международных обязательств на внутригосударственном уровне, включая формально определенные способы инкорпорирования международно-правовых норм в национальную правовую систему» [6]. Впервые на уровне монографии данная проблема была исследована А.С. Гавердовским [7, с. 62].

С позиции зарубежных исследователей в разных государствах неодинаковы механизмы интеграции Конвенции в правовую систему [8, с. 226], а значит, различаются качественные и количественные показатели, определяемые различием действующего и подлежащего внедрению правопорядка. С таким подходом следует согласиться ввиду того, что появляется разумное объяснение различия в уровне правовой защищенности в разных странах, приступивших к совершенствованию национальной правовой системы приблизительно в один и тот же промежуток времени.

Ситуация дополнительно осложнялась языковым барьером: постановления ЕСПЧ были изложены на английском и французском языках, а официальные полнотекстовые переводы попрежнему недоступны, разъяснения высших судебных инстанций всю практику ЕСПЧ охватить были не в состоянии. Постепенный переход к открытости регулирования правоотношений и нормами международного права, и практикой ЕСПЧ потребовал дополнительного внимания со стороны Верховного [9] и Конституционного [10] судов Российской Федерации. Важное значение конвенционным положениям придавал и председатель Конституционного суда РФ В.Д. Зорькин [11]. Наделяя вопросы восприятия практики ЕСПЧ самостоятельным значением, он указывал: «Мы исходим из того, что нарушения прав и свобод могут быть связаны с дефектами того или иного российского закона... ЕСПЧ может указать на дефекты нашего законодательства...» [12].

В постановлении Пленума Верховного суда РФ от 27 июня 2013 г. № 21 «О применении судами общей юрисдикции Конвенции о защите прав человека и основных свобод от 4 ноября 1950 г. и Протоколов к ней» указано, что правовые позиции Европейского суда по правам человека, изложенные в постановлениях по делам против России, являются обязательными для национальных судов, а по другим делам - подлежат учету (п. 2) [13].

На данном этапе необходимость и оправданность диалога всеми участниками воспринимались адекватно: и Совет Европы в лице ЕСПЧ, и Российская Федерация как частый ответчик согласились с мнением, что права человека следует защищать вместе с государствами, а не против них.

Учитывая опыт взаимодействия России и ЕСПЧ, стоит отметить, что периодически проявлялись несоответствия европейского и отечественного подходов к восприятию закрепленных прав человека. Например, в деле «Константин Маркин против Российской Федерации» ЕСПЧ посчитал 
нарушенным принцип гендерного равенства, а наша страна сослалась на особый статус военнослужащего, не предполагавший предоставление заявителю отпуска по уходу за ребенком [14].

С 2014 г. взаимоотношения России и Совета Европы ухудшились, что западные страны объясняли в том числе как результат грубого нарушения норм международного права с нашей стороны ввиду присоединения Крыма и Севастополя на основании референдума. Споры по этой ситуации продолжаются, и ни одна из сторон не предлагает компромиссного варианта разрешения: деструктивная критика действий РФ на внешнеполитической арене достигла абсурда, что неоднократно вызывало обеспокоенность на уровне Министерства иностранных дел России. Параллельно официальные лица нашего государства стали обращать внимание на политический окрас выносимых ЕСПЧ постановлений, что противоречило самой идее взаимодействия в Совете Европы; их содержательная часть приобрела характер недвусмысленного расхождения с положениями внутреннего права, в том числе Конституции России.

Проанализировав опыт других стран (в частности, Германии), 14 июля 2015 г. Конституционный суд РФ указал, что правовые позиции ЕСПЧ не отменяют приоритет Конституции, которая в порядке исключения может отступить от выполнения возлагаемых на нее обязательств в целях защиты основополагающих принципов и норм основного документа (п. 2.2). Впоследствии были внесены изменения в федеральный закон «О Конституционном суде РФ» [15]: инстанция получила право рассматривать вопрос о возможности исполнения постановлений ЕСПЧ при выявлении угрозы нарушения положений Конституции и основ конституционного строя.

19 апреля 2016 г. (по ранее рассмотренному ЕСПЧ делу «Анчугов и Гладков против России» [16]) была установлена невозможность наделения избирательными правами лиц, приговоренных к лишению свободы, в момент отбытия наказания (путем внесения изменений в законодательные акты) [17]. По мнению В.И. Торговченкова, таким образом государство не отказывается от исполнения Конвенции, но акцентирует внимание на приоритете положений Конституции на территории Российской Федерации [18].

Ответная реакция Совета Европы - недвусмысленное негодование западных коллег и опасение полномасштабного отказа следовать практике международного судебного органа в обозримом будущем. Однако на момент высказывания такой печальный прогноз не мог претендовать на достаточную степень вероятности, что влекло признание его «пессимистическим», тем более что на национальном уровне практика Европейского суда по правам человека во многих проявлениях для отечественной системы крайне важна. Например, в постановлении от 16 июня 2015 г. по делу «Назаренко против Российской Федерации» суд пришел к выводу о возможности реализации права на общение с ребенком даже при отсутствии биологического отцовства, но при условии наличия фрактически сложившихся семейных отношений и тесной эмоциональной связи (ребенок воспринимал небиологического отца как «папу») [19]. По нашему мнению, вынесенное ЕСПЧ постановление полностью соответствует интересам ребенка, но принятие такого решения на основании российского права невозможно.

Несмотря на критику практики ЕСПЧ, невозможно отрицать ее системный характер, органическое единство и полезность для развития системы прав и свобод человека. Профессор Т.Н. Нешатаева, объясняя особенности создания принципов права в практике ЕСПч, указывает на формирование «эволюционирующего прецедента» как объединения различных судебных практик, способного к принятию нового правила. Автор условно подразделяет прецеденты ЕСПЧ на «жесткие» («пилотные» постановления, указывающие на системные проблемы) и «мягкие» [20].

Зарубежные исследователи уважительно относятся к практике ЕСПЧ, отмечая уникальность самого судебного разбирательства, позволяющего гарантировать следующее:

1) возможность заявителей исключать негативное влияние авторитета официальных государственных лиц - международный судебный орган формально не связан обязательствами перед странами-участниками;

2) гибкость подходов суда к вопросам приемлемости жалоб;

3) правовую определенность в позиции ЕСПЧ - указание национальным судам на собственную ошибочную практику, нарушающую гарантированные Конвенцией права;

4) «прозрачность» в позиции национальных судов - призыв со стороны ЕСПЧ обеспечить при вынесении решения на национальном уровне понимание заявителем, почему состоялось (было вынесено) конкретное решение и почему оно не могло быть вынесено при схожих, но не идентичных обстоятельствах, что представляет собой защиту от «механического» правосудия [21, р. 16-17].

Финальным «аккордом» нетерпимости к России со стороны Совета Европы стало лишение нашей делегации права голоса в Парламентской ассамблее, на что мы ответили отказом перечисления взносов и формированием бюджетного дефицита самой международной организации. Совет Европы впоследствии неоднократно высказывался в пользу исключения РФ из своего со- 
става за нарушение финансовой дисциплины (август 2019 г.). На момент завершения исследования российская делегация была полностью восстановлена в правах в Совете Европы при условии погашения задолженности, что наше государство и предлагало изначально.

Мы разделяем обеспокоенность отечественных теоретиков и практиков по поводу непоследовательности решений ЕСПЧ при рассмотрении жалоб против Российской Федерации, но склонны полагать, что Европейский суд по правам человека способен привнести существенный вклад в развитие системы прав и свобод человека во внутринациональном пространстве. Так, британские исследователи называют ЕСПЧ самым эффективным (широко признаваемым) международным регулятором по обеспечению соблюдения прав человека в мире [22, р. 180] и, постулируя развитость собственного механизма защиты прав человека, не отказываются от восприятия опыта ЕСПЧ.

Авторитетные подходы Верховного и Конституционного судов Российской Федерации, постепенное вовлечение элементов практики ЕСПЧ в отечественное правоприменение и обеспечение адаптации полнотекстовых решений для национальной судебной практики - это бесконечно полезные наработки, отказ от которых для государства, признающего права и свободы человека высшей ценностью, недопустим.

\section{Ссылки:}

1. Конвенция о защите прав человека и основных свобод : заключена в г. Риме 4 нояб. 1950 г. // Собрание законодательства РФ. 1998. № 20. Ст. 2143.

2. О ратификации Конвенции о защите прав человека и основных свобод и Протоколов к ней [Электронный ресурс] : федер. закон от 30 марта 1998 г. № 54-Ф3. Доступ из справ.-правовой системы «КонсультантПлюс».

3. Конституция РФ : принята всенародным голосованием 12 дек. 1993 г. // Собрание законодательства РФ. 2014. № 31. Ст. 4398.

4. Международное право : учебник для студентов вузов, обучающихся по специальности «Юриспруденция» / Б.М. Ашавский, М.М. Бирюков, В.Д. Бордунов, С.А. Егоров и др. 4-е изд., стер. М., 2011. 831 с.

5. Марченко М.Н. Юридическая природа и характер решений Европейского суда по правам человека // Государство и право. 2006. № 2. С. 11-19.

6. Червонюк В.И. Имплементация решений ЕСПЧ в национальное законодательство (современный контекст) // Конституционное и муниципальное право. 2017. № 7. С. 15-21.

7. Гавердовский А.С. Имплементация норм международного права. Киев, 1980. 320 с.

8. Люббе-Вольфф Г. Европейский суд по правам человека и национальные суды: дело Гергюлю // Имплементация решений Европейского суда по правам человека в практике конституционных судов стран Европы : сборник докладов. М., 2006. С. 224-231.

9. О применении судами общей юрисдикции общепризнанных принципов и норм международного права и международных договоров РФ [Электронный ресурс] : постановление Пленума Верховного суда РФ от 10 окт. 2003 г. № 5 : в ред. от 5 марта 2013 г. Доступ из справ.-правовой системы «КонсультантПлюс».

10. По делу о проверке конституционности положений статей 16, 20, 112, 336, 376, 377, 380, 381, 382, 383, 387, 388 и 389 Гражданского процессуального кодекса РФ в связи с запросом Кабинета министров Республики Татарстан, жалобами открытых акционерных обществ «Нижнекамскнефтехим» и «Хакасэнерго», а также жалобами ряда граждан : постановление Конституционного суда РФ от 5 февр. 2007 г. № 2-П // Собрание законодательства РФ. 2007. № 7. Ст. 932.

11. Зорькин В.Д. Имплементация решений Европейского суда по правам человека в практике конституционных судов стран Европы [Электронный ресурс] : выступление на VIII Международном фроруме по конституционному правосудию // Конституционный суд РФ : официальный сайт. 2005. 1 дек. URL: http://www.ksrf.ru/ru/News/Speech/Pages/ViewItem.aspx?Paramld=16 (дата обращения: 03.07.2019).

12. Зорькин В.Д. Выступление председателя Конституционного суда РФ : редакционный материал // Российский судья. 2009. № 1. С. $16-24$.

13. О применении судами общей юрисдикции Конвенции о защите прав человека и основных свобод от 4 нояб. 1950 г. и Протоколов к ней : постановление Пленума Верховного суда РФ от 27 июня 2013 г. № 21 // Российская газета. 2013. 5 июля.

14. По делу «Константин Маркин (Konstantin Markin) против Российской Федерации» [Электронный ресурс] : постановление ЕСПЧ от 22 марта 2012 г. : жалоба № 30078/06. Доступ из справ.-правовой системы «Гарант».

15. О Конституционном суде РФ [Электронный ресурс] : федер. конституционный закон от 21 июля 1994 г. № 1-ФКЗ : в ред. от 14 дек. 2015 г. Доступ из справ.-правовой системы «Гарант».

16. По делу «Анчугов и Гладков (Anchugov and Gladkov) против Российской Федерации» [Электронный ресурс] : постановление ЕСПЧ от 4 июля 2013 г. : жалобы № 11157/04, 15162/05. Доступ из справ.-правовой системы «Гарант».

17. По делу о разрешении вопроса о возможности исполнения в соответствии с Конституцией Российской Федерации постановления Европейского суда по правам человека от 4 июля 2013 г. по делу «Анчугов и Гладков против России» : постановление Конституционного суда РФ от 19 апр. 2016 г. № 12-П : в связи с запросом Министерства юстиции РФ // Собрание законодательства РФ. 2016. № 17. Ст. 2480.

18. Торговченков В.И. Влияние Европейского суда по правам человека на правовую систему Российской Федерации // Законность. 2016. № 11. С. 32-36.

19. По делу «Назаренко (Nazarenko) против России» [Электронный ресурс] : постановление ЕСПЧ от 16 июля 2015 г. : жалоба № 39438/13. Доступ из справ.-правовой системы «Гарант».

20. Нешатаева Т.Н. Решения Европейского суда по правам человека: новеллы и влияние на законодательство и правоприменительную практику. М., 2013. 303 с.

21. Gerards J.H., Glas L.R. Access to Justice in the European Convention on Human Rights System // Netherlands Quarterly of Human Rights. 2017. Vol. 35, no. 1. P. 11-30. https://doi.org/10.1177/0924051917693988.

22. Donald A., Gordon J., Leach Ph. The UK and the European Court of Human Rights [Электронный ресурс] : Research Report 83 // Equality and Human Rights Commission. 2012. URL: https://www.equalityhumanrights.com/sites/default/files/83._european_court_of_human_rights.pdf (дата обращения: 03.07.2019). 


\section{References:}

Ashavsky, BM, Biryukov, MM, Bordunov, VD \& Egorov, SA (et al.) 2011, International Law: a Textbook, 4th ed., Moscow, 831 p., (in Russian).

Chervonyuk, VI 2017, 'Implementation of ECtHR Judgements in National Legislation (Modern Context)', Konstitutsionnoe i munitsipal'noe pravo, no. 7, pp. 15-21, (in Russian).

Donald, A, Gordon, J \& Leach, Ph 2012, 'The UK and the European Court of Human Rights: Research Report 83', Equality and Human Rights Commission, viewed 03 July 2019, <https://www.equalityhumanrights.com/sites/default/files/83._european court of human rights.pdf>.

Gaverdovsky, AS 1980, Implementation of the Rules of the International Law, Kiev, 320 p., (in Russian).

Gerards, JH \& Glas, LR 2017, 'Access to Justice in the European Convention on Human Rights System', Netherlands Quarterly of Human Rights, vol. 35, no. 1, pp. 11-30, https://doi.org/10.1177/0924051917693988.

Lubbe-Wolff, G 2006, 'European Court of Human Rights and National Courts: the Case of Gergülu', Implementation of European Court of Human Rights Judgements in the Case-Law of Constitutional Courts of European Countries: Collected Reports, Moscow, pp. 224-231, (in Russian).

Marchenko, MN 2006, 'The Legal Nature and the Manner of Decisions of the European Court of Human Rights', Gosudarstvo i pravo, no. 2, pp. 11-19, (in Russian).

Neshataeva, TN 2013, European Court of Human Rights Judgements: Novels and the Impact on Legislation and Law Enforcement Practice, Moscow, 303 p., (in Russian).

Torgovchenkov, VI 2016, 'The Impact of the European Court of Human Rights on the Legal System of the Russian Federation', Zakonnost', no. 11, pp. 32-36, (in Russian).

Zorkin, VD 2005, 'Implementation of European Court of Human Rights Judgements in the Case-Law of Constitutional Courts of European Countries: a Speech at the 8th International Forum on Constitutional Justice', Official Website of the Constitutional Court of the Russian Federation, December 01, viewed 03 July 2019, <http://www.ksrf.ru/ru/News/Speech/Pages/ViewItem.aspx?Paramld=16>, (in Russian).

Zorkin, VD 2009, 'Speech by the Chairman of the Constitutional Court of the Russian Federation: an Editorial Copy', Rossiyskiy sud'ya, no. 1, pp. 16-24, (in Russian). 